\title{
ROTATIVIDADE DE TREINADORES E O DESEMPENHO DAS EQUIPES DE FUTEBOL NO BRASIL
}

\author{
Caio Oliveira Azevedo * \\ Aléssio Tony Cavalcanti de Almeida ${ }^{\dagger}$ \\ Hilton Martins de Brito Ramalho ${ }^{\ddagger}$
}

\begin{abstract}
Resumo
Este trabalho analisa as consequências de mudanças de treinadores no transcorrer de uma competição. Foram usados dados de nove temporadas do futebol brasileiro, com indicadores de resultado dos times rodada-arodada e informações de casas de apostas. A partir das estimativas obtidas, foram percebidas melhoras em várias medidas de desempenho após a substituição de treinador, considerando o jogo seguinte à mudança. No entanto, esse efeito acaba sendo estatisticamente não significativo, quando analisado sobre uma maior quantidade de jogos após a mudança. Dessa forma, verifica-se que a mudança de treinador não se mostra uma estratégia efetiva de melhoria de desempenho.
\end{abstract}

Palavras-chave: rotatividade, técnico, desempenho, futebol, Brasil. Códigos JEL: C15, C23, C55.

\begin{abstract}
This studies aims to evaluate the consequences of in-season changes of head-coach on the performance. Data from nine seasons were used, with turn-by-turn team result indicators and bookmaker information. From the estimates obtained, improvement in several measures of performance after the substitution of coach was noticed, considering the game following the change. However, this effect turns out to be statistically insignificant, when analyzed on a larger number of games after the change. Thus, it turns out that the change of coach does not show itself as an effective strategy to improve performance.
\end{abstract}

Keywords: turnover, head-coach, performance, soccer, Brazil. JEL codes: C15, C23, C55.

DOI: http://dx.doi.org/10.11606/1980-5330/ea 171487

\footnotetext{
* Programa de Pós-Graduação em Economia, Universidade Federal da Paraíba. E-mail: caio.azevedo@live.com

${ }^{\dagger}$ Departamento de Economia, Universidade Federal da Paraíba. E-mail: alessi o@ccsa.ufpb.br

‡ Departamento de Economia, Universidade Federal da Paraíba. E-mail: hilton@ccsa.ufpb.br
} 


\section{Introdução}

Mundialmente o Brasil é conhecido como o "País do Futebol", e essa paixão nacional é também uma preferência global, já que o futebol é a modalidade esportiva mais popular do planeta, seja pela maior quantidade de praticantes ao redor do mundo (FIFA 2007) ou pelo maior número de seguidores espalhados pelas redes sociais ${ }^{1}$. A preferência em torno do futebol faz desse esporte um mercado valioso do ponto de vista econômico. Segundo dados da análise econômico-financeira dos clubes de futebol do Brasil, realizada por Itaú BBA (2018), os 20 clubes da primeira divisão do Campeonato Brasileiro em 2017 somaram uma receita bruta total de $\mathrm{R} \$ 4,93$ bilhões, obtendo um crescimento real de $13,3 \%$ quando comparado ao ano anterior.

No Brasil, além de símbolo nacional ao lado do carnaval, o futebol exerce um papel social e econômico de extrema relevância. A produção de entretenimento ocasionada pelos jogos de futebol impacta não somente a cadeia de negócios envolvidos diretamente ao espetáculo, mas também tem reflexos, por externalidades, em outros diversos segmentos da economia, acarretando em geração de emprego e renda (Nascimento et al. 2015).

Tamanha a sua importância, enquanto fenômeno de interesse social e econômico, que nos últimos anos tem mostrado ser uma área densa para pesquisas científicas, ${ }^{2}$ por permitir uma gama de análises pela regularidade, variabilidade e alta frequência de dados (Ter Weel 2011). Szymanski (2003), por exemplo, argumenta que os dados provenientes dos esportes podem fornecer informações importantes sobre o comportamento do mercado de trabalho e Kahn (2000) complementa denominando o setor de esportes como um valioso laboratório para o mercado de trabalho.

Nesse contexto, na análise de Guzmán (2006), os clubes de futebol são um tipo de negócio especial. Para o autor, diferentemente de empresas, que buscam apenas o bom desempenho financeiro, os clubes têm a obrigação imprescindível de obter êxito esportivo. É evidente que a existência de um clube de futebol está condicionada à obtenção de resultados financeiros satisfatórios, todavia, estes somente terão uma trajetória de crescimento sustentado mediante o bom desempenho esportivo.

Em tal caso, a busca pelo êxito esportivo, torna o técnico uma das figuras centrais no futebol, pelas diversas e importantes funções que exerce dentro de um clube. Além da incumbência de coordenar a formação da equipe, auxiliando no processo de dispensas, contratações e renovações de jogadores, cabe ao técnico a responsabilidade de liderança junto ao elenco e o desenvolvimento das opções táticas dentro dos jogos, escalando os atletas mais preparados.

Assim, se o papel desenvolvido por técnicos de futebol é preponderante ou não negligenciável para o êxito esportivo, conforme afirmam Anderson \& Sally (2013), é de se esperar a troca em caso de resultados negativos sucessivos, objetivando um melhor desempenho (Rocha et al. 2009). Nesse caso, os diretores envolvidos no processo de decisão comparam o desempenho real às expectativas. Se acreditarem que o rendimento está abaixo do esperado, a probabilidade de uma substituição ocorrer aumenta (Van Ours \& Van Tuijl 2016).

\footnotetext{
${ }^{1}$ O termo World Cup, foi o mais buscado no ano de 2018 no Brasil e no mundo (Google 2018).

${ }^{2}$ Ver Szymanski \& Kuper (2010), Dobson \& Goddard (2001), Paola \& Scoppa (2012)
} 
No que tange às expectativas em relação aos técnicos de futebol, Van Ours \& Van Tuijl (2016) mostraram que odds cotadas por sites de apostas são capazes de especificar expectativas imparciais sobre o desempenho de uma equipe. Convém destacar que apostadores são agentes racionais, que visam a maximização de seus ganhos dispondo de um conjunto grande de informações, não se restringindo somente a torcedores, que eventualmente poderiam exercer uma expectativa mais viesada.

O intuito então da utilização de probabilidades de apostas é quantificar a crença dos apostadores em relação a diversas características do time que são subjetivas, como a qualidade do elenco, o trabalho desenvolvido pelo técnico, a gestão da diretoria etc. Sendo assim, Van Ours \& Van Tuijl (2016) demonstram empiricamente a boa adequação das probabilidades de sites de apostas como proxy para mensurar a expectativa de desempenho em relação ao time. Tal variável, denominada como "indicador de surpresa", capta a diferença entre o número de pontos conquistados no jogo e o valor esperado obtido pelas probabilidades dos sites de apostas.

Diante de todo exposto, é imediato perceber que os campeonatos de futebol profissional apresentam uma direção favorável para se investigar os efeitos das mudanças de técnicos. Nessa sequência, o caso do Brasil merece destaque, uma vez que as equipes da primeira divisão apresentam uma alta média de mudança de treinadores, de duas até quatro vezes maior que os clubes da elite do campeonato Alemão, Espanhol e Francês ${ }^{3}$. Dada a escassez de pesquisas direcionadas a campeonatos com alta rotatividade de treinadores, este trabalho visa avaliar os efeitos de mudanças dos técnicos sobre o desempenho dos principais clubes de futebol do Brasil. Para tanto, foram usados dados de nove temporadas (2009 a 2017) da primeira divisão do Campeonato Brasileiro.

Tomando por base Van Ours \& Van Tuijl (2016), a estratégia empírica deste estudo é feita em dois estágios sequenciais, o primeiro é a aplicação de técnicas de pareamento baseadas no resultado do índice de surpresa acumulada dos clubes no campeonato e o segundo é a utilização do estimador de diferenças-em-diferenças (diff-in-diff) em uma estrutura de dados em painel, visando identificar o efeito da mudança de treinador.

Em termos de agregação de resultados para a literatura de Economia do Esporte, esta pesquisa se diferencia da literatura especializada sobre o assunto em dois aspectos principais: (i) ao usar dados referentes a mudanças de técnico no futebol brasileiro, que além de permitir trabalhar como um maior número de observações, traz uma relevância ao tema, devido a importância exercida pelo Brasil no futebol mundial; (ii) ao apresentar uma perspectiva inédita por meio da avaliação dos efeitos em diferentes maturidades de tempo.

Nesse último aspecto, avalia-se o efeito a partir de um jogo, dois jogos e assim sucessivamente, após a mudança de treinador e não somente o efeito ao final da temporada, conforme aplicado na literatura (Van Ours \& Van Tuijl 2016, Besters et al. 2016). Portanto, o objetivo geral do artigo é avaliar o efeito médio da rotatividade de treinadores sobre o desempenho dos clubes brasileiros, efetuando análises jogo-a-jogo após a mudança.

Além desta introdução, este artigo se divide em mais 5 seções. A próxima apresenta a revisão da literatura, contextualizando todo o debate atual exis-

\footnotetext{
${ }^{3} \mathrm{Na}$ temporada de 2018 do Campeonato Brasileiro foram feitas 29 mudanças de treinador, enquanto que na temporada 2017/2018 dos Campeonatos Alemão, Espanhol e Francês, ocorreram 9,13 e 7 mudanças, respectivamente.
} 
tente acerca do efeito da rotatividade de técnicos sobre o desempenho de equipes de futebol. Já a terceira seção, evidencia os procedimentos metodológicos, incluindo descrição dos dados e estratégia empírica. A quarta e quinta seção apresentam os resultados da pesquisa, enquanto a sexta seção expõe as considerações finais. Por fim, detalhes adicionais sobre a construção de dados e geração dos resultados, tabelas e figuras estão disponíveis em scripts em $\mathrm{R}$ e Python para replicação, contidos no Apêndice Suplementar e disponível na página https://github.com/caio-azevedo/rotatividade_treinadores.

\section{Revisão da Literatura}

Esta seção apresenta estudos seminais referentes à temática do presente artigo, além de contextualizar o histórico de desenvolvimento e contribuição de estudos empíricos acerca do efeito da rotatividade de técnicos sobre o desempenho de equipes de futebol.

De forma mais ampla, estudos baseados em dados esportivos não estão susceptíveis a uma única interpretação acerca da eficácia da rotatividade de técnicos no desempenho da equipe. Boa parte dos estudos analisando as ligas profissionais de futebol na Alemanha, Inglaterra e Holanda encontram comprovações de que a rotatividade de técnico não tem impacto sobre o desempenho da equipe (Salomo et al. 2000, Poulsen 2000, Bruinshoofd \& Weel 2003). Além desses resultados, existem trabalhos, como Tena \& Forrest (2007), que ao estudar o futebol profissional da Espanha, entre os anos de 2002 a 2005, demonstraram que a rotatividade causa impacto modesto no desempenho da equipe, sendo o efeito impulsionado apenas pela melhoria de performance durante os jogos como mandante.

Vale a pena ressaltar que estudos mais antigos sobre a rotatividade de técnicos são baseados em modelos simples, que não consideravam, por exemplo, a qualidade dos adversários que as equipes dos novos e dos antigos treinadores enfrentaram durante uma temporada. Aliás, tal variável pode ser bastante significativa para explicar os efeitos da demissão sobre o desempenho das equipes e, portanto, caso essa qualidade seja desconsiderada, as estimativas obtidas poderão ser tendenciosas (Paola \& Scoppa 2012).

Nesse sentido, estudos mais recentes passaram a levar em consideração essa constatação. Koning (2003), por exemplo, investigando o futebol holandês durante as temporadas 1993/94 à 1997/98 e controlando pela qualidade dos adversários, concluiu que a alteração de técnico acarreta na queda de desempenho da equipe. Já Balduck et al. (2010) não encontraram efeitos na demissão de técnicos ao estudar os dados do futebol belga, entre as temporadas de 1998 a 2005. Mesma conclusão foi a de Paola \& Scoppa (2012) ao analisar o futebol italiano entre as temporadas de 1997 a 2009. Nesse caso, controlaram a qualidade dos adversários ao considerar a posição na tabela das equipes na temporada passada ou os pontos acumulados até a rodada considerada.

Outro problema econométrico que era desconsiderado em trabalhos mais antigos é que técnicos não são demitidos aleatoriamente e sim após uma sequência de maus desempenhos de sua equipe (Audas et al. 1999, Dobson \& Goddard 2001, D'Addona \& Kind 2014). A esse respeito, é comum observar que sequências de resultados excepcionalmente baixos são estatisticamente seguidas por uma recuperação, esse fenômeno é conhecido como regressão à média, ou seja, resultados que tendem a estar mais próximos da média. Logo, mode- 
los naive que simplesmente comparam a performance anterior à dispensa do técnico com o desempenho após a demissão, pode levar a conclusões errôneas, visto que os resultados poderiam ter melhorado também sem a demissão do técnico.

Quando levamos em conta o fato de que a demissão de um treinador não é um evento puramente exógeno, ao estudar a eficácia da rotatividade de técnicos, o critério pelo qual foi demitido deve ser levado em consideração. Geralmente, os estudos que consideram os critérios ou a seletividade das demissões, utilizam a estratégia de determinar um grupo de controle com técnicos que não foram demitidos, mesmo que tenham obtido desempenho insatisfatório semelhante ao desempenho daqueles que efetivamente foram dispensados.

Van Ours \& Van Tuijl (2016), estudando o futebol profissional holandês por 14 temporadas (2000/2001 - 2013/2014), corrigem os dois problemas relacionados, controlando a qualidade dos adversários e também a seletividade das demissões por meio da definição de um contrafactual. Primeiramente, investigam se o indicador de surpresa acumulada, que captura a soma das diferenças entre o número de pontos conquistados e o valor esperado de pontos, baseado nas probabilidades de sites de apostas, é um determinante para a demissão de técnicos.

Nesse contexto, apresentam como novidade uma estratégia para combinar as mudanças reais de técnico com as observações contrafactuais, por meio da utilização do indicador de surpresa acumulada. Em consonância com a maioria dos estudos anteriores, os autores concluem que o desenvolvimento de performances em torno do tempo da substituição do treinador está sujeito à regressão à média. Entretanto, esse estudo se baseia em um campeonato de futebol com baixa rotatividade de técnico e, além disso, não ocorre distinção se há ou não efeitos da rotatividade em diferentes maturidade de tempo. Sendo assim, este artigo visa preencher essas duas lacunas.

Já em relação a estudos que utilizam o futebol brasileiro, pouco, relativamente, foi produzido até o momento na temática de economia do esporte diante da relevância do Brasil no cenário do futebol mundial. Ainda assim, é possível destacar alguns trabalhos seminais, como é o caso do estudo desenvolvido por Giovannetti et al. (2006), Rocha et al. (2009).

O primeiro estudo mede a fidelidade das torcidas brasileiras. A ideia dos autores é investigar se a decisão dos torcedores de ir ao estádio assistir a partida do seu time é influenciada pela probabilidade de vitória do mesmo. Em caso de resposta afirmativa, considera-se o torcedor como infiel. Concluindo que as torcidas são predominantemente fiéis, sendo exceção as torcidas de alguns poucos clubes.

Já o segundo estudo utiliza um modelo de economia política para explicar a permanência dos treinadores no futebol brasileiro. De acordo com a análise empírica e em consonância com as previsões do modelo teórico, a atuação de um treinador é fundamental para determinar a sua continuidade no clube, ou seja, foi possível concluir que o fator mais importante na determinação da gestão de um treinador é precisamente o seu desempenho enquanto comandante de sua equipe.

Além disso, em linha com os trabalhos seminais, recentemente alguns autores têm juntado esforços para introduzir a teoria econômica no estudo do futebol brasileiro e colaborar com a temática da Economia do Esporte, podendo destacar os estudos desenvolvidos por Alves et al. (2019), Araujo et al. (2018), Gasparetto \& Barajas (2018). 


\section{Procedimentos Metodológicos}

\subsection{Dados}

Os dados acerca do futebol brasileiro não estão disponíveis oficialmente de forma estruturada, sendo assim, sua coleta exigiu a adoção de técnicas de web scrapping (mineração de dados não estruturados da Web), além de diversas rotinas para verificar a consistência dos dados obtidos. Portanto, devido à questão de estruturação dos textos disponíveis, os dados empregados neste trabalho foram oriundos de duas fontes principais, que são: (a) Wikipédia ${ }^{4}$; (b) dados de sites de apostas ${ }^{5}$. Os dados coletados da Wikipédia configuram um conjunto de variáveis que formam uma base de dados de mudanças de técnico. Já as informações obtidas dos sites de apostas descrevem os jogos datas, horário, placar e odds (risco) para o mandante, visitante e empate. A partir destes, são obtidas as probabilidades de vitória, empate e derrota.

O método mais comumente usado para transformar odds cotadas pelos apostadores em estimativas de probabilidade é a BN (Basic normalization) - dividindo as probabilidades inversas pelo seu somatório total (Štrumbelj 2014).

$$
P r_{j}=\frac{\frac{1}{o d d s_{j}}}{\left(\frac{1}{o d d s_{v}}+\frac{1}{o d d s_{d}}+\frac{1}{o d d s_{e}}\right)}, \quad j \in[v, d, e]
$$

com $j$ representando vitória $(v)$, derrota $(d)$ e empate $(e)$.

Após a obtenção de tais probabilidades (equação (1)), as mesmas foram usadas no cálculo do valor esperado de pontos (equação (2)) em cada partida realizada, de tal modo:

$$
E(\text { pontos })=3 \times P r_{\text {vitoria }}+1 \times \operatorname{Pr}_{\text {empate }}{ }^{6}
$$

Nesse sentido, o denominado indicador de surpresa é expresso pela diferença entre o número de pontos conquistado no jogo e o esperado (Van Ours \& Van Tuijl 2016). Portanto, o indicador de surpresa acumulada trata-se simplesmente da soma acumulada da equação (3) por jogo, para o time analisado.

$$
\text { Surpresa }=\text { pontos }-E(\text { pontos })
$$

A base de dados, então, foi formada por meio dos dados elencados acima correspondente a nove temporadas - de 2009 até 2017 - da Primeira Divisão do Campeonato Brasileiro de Futebol. Cada temporada contém 20 clubes que competem de acordo com um formato de todos contra todos, resultando em 380 jogos por ano e um total de 3.420 partidas no período considerado.

É importante ressaltar que por se tratar de dados não estruturados e coletados de diversas fontes, foi necessário executar diversas rotinas de conferência

\footnotetext{
${ }^{4}$ Disponível em: https://pt.wikipedia.org/wiki/Campeonato_Brasileiro_de_Futebol. Acesso em: 16 jun. 2018. 2018.

${ }^{5}$ Disponível em: https : / /www.oddsportal .com/soccer/brazil. Acesso em: 10 nov.

${ }^{6}$ No futebol, por definição da FIFA (Federação Internacional de Futebol), cada vitória rende ao time 3 pontos, enquanto que um empate e uma derrota, rendem 1 e 0 ponto, respectivamente. Essa regra passou a valer no futebol desde a Copa do Mundo de 1994.
} 
dos dados obtidos, a fim de estabelecer garantias de que a base de dados formada não continha erros.

Um exemplo importante para garantir a fidedignidade dos dados foi a junção das duas bases de dados obtidas. Inicialmente se construiu duas bases, a primeira contendo informações sobre os jogos e a segunda sobre as mudanças de técnicos. Nesse sentido, era importante garantir que na junção entre as tabelas, as correspondências fossem feitas corretamente.

Para tanto, foi desenvolvido um código de identificação com o intuito de facilitar a junção. Em síntese, este é formado por meio da concatenação das variáveis: ano, rodada, time mandante, time visitante e uma variável binária, que assume o valor 1 , se o time analisado for o mandante, ou 2, caso ele seja o visitante. Usando como exemplo, o jogo entre Flamengo e Barueri na $13^{\mathrm{a}}$ rodada do Campeonato Brasileiro de 2009, analisado sob a ótica do Flamengo, o código se formataria da seguinte forma: 200913FLABAR1. Portanto, os códigos de identificação construídos em ambas as tabelas teriam o mesmo padrão, propiciando as correspondências corretas entre os dados de bases distintas.

Tabela 1: Relação das variáveis obtidas na base de dados de mudanças de técnico.

\begin{tabular}{ll}
\hline Variável & Descrição \\
\hline cod & Código para a junção das tabelas. \\
time & O time que está sendo analisado na troca de técnico. \\
mt_antecessor & O nome do técnico que foi substituído. \\
mt_motivo & O motivo para a troca de técnico. \\
mt_ultimo_jogo & O último jogo do campeonato brasileiro anterior a troca. \\
condição & A condição do time que está sendo analisado, se é mandante \\
& ou visitante. \\
mt_sucessor & O nome do técnico que assumiu o time. \\
temporada & Ano ou temporada em que a troca de técnico foi realizada. \\
mt_data & A data que foi realizada a troca de técnico. \\
mt_rodada & A rodada a qual foi realizada a troca de técnico. \\
mt_posicao & A posição na rodada do time analisado após a computação do \\
& placar do jogo.
\end{tabular}

Fonte: Elaboração própria a partir dos dados da Wikipédia e da CBF.

Além disso, foram estabelecidas algumas variáveis por meio de técnicas de programação, como a posição do time e do adversário na rodada, que tiveram papel estratégico no desenvolvimento da pesquisa. Primeiro, pelo fato dessas serem importantes para medir a qualidade não observada entre clubes ou entre temporadas do mesmo clube e, segundo, por servirem como rotina de conferência, visto que a partir delas se tornou executável a geração da classificação final de cada ano, possibilitando assim a comparação com a classificação disponibilizada pela CBF (Confederação Brasileira de Futebol) ${ }^{7}$.

Por fim, obteve-se uma base de dados unificada com a descrição de cada jogo e com as mudanças de técnicos ocorridas por rodada em cada tempo-

${ }^{7}$ Disponível em: 
Tabela 2: Relação das variáveis obtidas na base de dados de jogos.

\begin{tabular}{ll}
\hline Variável & Descrição \\
\hline ccod & Código para junção das tabelas. \\
rodada & A rodada a qual a partida pertence. \\
temporada & Ano ou temporada em que o campeonato foi disputado. \\
data & A data da partida. \\
jogo & Os times que disputaram a partida. \\
placar & O placar final da partida. \\
odds_mandante & A odds média para a vitória da equipe mandante na partida. \\
odds_empate & A odds média para o empate na partida. \\
odds_visitante & A odds média para a vitória da equipe visitante na partida. \\
site_apostas & A quantidade de sites de apostas usados para o cálculo das odds \\
time & médias. \\
pos_rodada & O time que está sendo analisado. \\
pos_adv_rodada & p posição na rodada do time analisado após a computação do \\
& A posição na rodada do time adversário após a computação do \\
placar do jogo.
\end{tabular}

Fonte: Elaboração própria a partir dos dados da OddsPortal.com. 
rada $^{8}$. A relação das variáveis obtidas nas duas bases de dados - mudanças de técnicos e jogos - podem ser visualizadas nas tabelas 1 e 2 , respectivamente.

\subsection{Estratégia empírica}

Sabendo que as estimativas que comparam o grupo de tratamento com um grupo de controle adequado levam a resultados mais consistentes em comparação com a abordagem do modelo naive (que não se preocupa com a construção de um cenário contrafactual), utilizou-se neste trabalho a abordagem empírica proposta por Van Ours \& Van Tuijl (2016) para a identificação dos efeitos de uma mudança de técnico sobre o desempenho dos clubes de futebol no Brasil. Basicamente, essa abordagem combina técnicas de pareamento com modelos de painel com efeito fixo.

O método de pareamento tem por escopo construir grupos de controle que mais se assemelhem ao cenário de tratamento (mudança de treinador), tendo por base o indicador de surpresa acumulada. Em seguida, o modelo de regressão em painel, com estimador de diff-in-diff (diferença-em-diferença), possibilita incluir controle para a heterogeneidade não observada entre os clubes, propiciando uma estimativa mais robusta e consistente.

\section{Estágio I - Modelo de pareamento}

Segundo Gertler et al. (2018), o método de pareamento utiliza, essencialmente, técnicas estatísticas para criar um grupo de controle artificial. Para cada possível unidade do grupo de tratamento, procura-se encontrar uma unidade de não tratamento (ou conjunto destas) que possua semelhantes características observáveis.

Considere, por exemplo, o objeto deste estudo que é avaliar o impacto da mudança de técnico sobre o desempenho de um time. Como mencionado, a demissão de um técnico não é um evento puramente exógeno, logo, não existe uma regra concreta para explicar o por que alguns são demitidos e outros não.

Nesse contexto, os métodos de pareamento permitem identificar o conjunto de observações onde os técnicos que não foram demitidos mais se parecem com as observações daqueles que de fato foram demitidos, utilizando como base as características disponíveis. Assim, essas observações pareadas, de técnicos que não foram demitidos, passam a ser o grupo de controle.

Portanto, determinar um bom par para cada mudança de técnico requer aproximar o máximo possível as características que explicam a decisão para tal alteração. Nesse sentido, se a quantidade de características relevantes observáveis for muito grande ou se cada característica assumir muitos valores, pode ser difícil identificar um pareamento para cada uma das unidades do grupo de tratamento. Essa situação é denominada como problema da dimensionalidade.(Rosenbaum \& Rubin 1983, Gertler et al. 2018)

Nesse sentido, Rosenbaum \& Rubin (1983) propuseram a utilização de uma função de $\mathbf{X}$ que resumisse toda a informação contida em tal vetor. Assim, sugeriram o denominado método de pareamento por escore de propensão (em inglês, Propensity score matching - PSM), ou seja, que a função de $\mathbf{X}$

\footnotetext{
${ }^{8}$ Para fins de transparência, os dados usados nesta pesquisa se encontram disponíveis para download em: https://github.com/caio-azevedp/rotatividade_treinadores/ blob/master/data/base.csv.
} 
representasse a probabilidade de receber o tratamento, dado o conjunto de caraterísticas observáveis.

A partir de então, é calculado o escore de propensão ${ }^{9}$ para todas as observações, o que viabiliza o pareamento das observações que tiveram mudança de técnico com as que não tiveram, de acordo com a proximidade do escore de propensão. Portanto, os escores de propensão são utilizados como uma forma de parear os grupos de tratamento e de controle, para isso, é necessário que existam observações (ou elementos) no grupo de controle, que tenham características similares às observações do grupo de tratamento, tal condição é denominada como sobreposição.

No caso do presente artigo, o interesse está em estimar a probabilidade de um técnico ser demitido, dado certas características de interesse, como o índice de surpresa acumulada, no intuito de obter o escore de propensão de cada observação. Diante das evidências sobre a análise dos determinantes para a demissão de técnico na literatura internacional, como Van Ours \& Van Tuijl (2016), Besters et al. (2016), e nas estimativas disponíveis no Apêndice A. para o caso do Brasil ${ }^{10}$, admite-se que a surpresa acumulada seja um fator exógeno relacionado com a demissão do técnico. Nessas condições, os escores de propensão do técnico ser demitido foram estimados via MQG (Mínimos Quadrados Generalizados), em que a função de densidade acumulada seguiu uma distribuição logística - Modelo Logit.

Convém no entanto destacar, que as observações são pareadas de acordo com a proximidade de seus escores e para isso existe uma extensa lista de algoritmos ${ }^{11}$ que auxiliam nesse processo, sendo o mais usual a técnica do vizinho mais próximo (Nearest Neighbor), adotada neste estudo.

Desse modo, o próximo passo para a identificação dos grupos foi determinar as correspondências de cada observação que tinha mudança de técnico, com observações que não tinham alteração do treinador. E assim, o algoritmo adotado selecionou os cinco vizinhos mais próximos, tendo em vista a minimização da distância de Mahalanobis para os escores de propensão obtidos (Rosenbaum \& Rubin 1983, Gertler et al. 2018).

Nessas condições, cada uma das 225 mudanças de técnicos poderia estar associada a no máximo 5 observações contrafactuais. Por outro lado, para a construção de um grupo de controle que fosse válido, era necessário impor requisitos, no sentido de associar uma substituição de técnico a um único caso contrafactual. Com esse objetivo, seguimos uma abordagem semelhante à adotada em Van Ours \& Van Tuijl (2016).

Nessa abordagem, para que a observação contrafactual fosse válida, era necessário que cumprisse os seguintes requisitos: (i) a observação diz respeito ao mesmo clube, mas decorre de uma temporada diferente;(ii) a consistência com as mudanças de técnicos reais exige que se exclua a correspondência com uma observação anterior ao quinto jogo e posterior $34^{\mathrm{a}}$ partida.

Finalmente, das 225 mudanças de técnicos ocorridas no Campeonato Brasileiro de Futebol no período entre 2009 a 2017, 140 obtiveram um contrafac-

\footnotetext{
${ }^{9}$ É importante observar que geralmente as probabilidades preditas de pertencimento ao grupo (ou escore de propensão) são obtidas com regressão logística (Gertler et al. 2018, Menezes et al. 2016).

${ }^{10}$ Por meio dessa análise pode se concluir que a surpresa acumulada é determinante para a rotatividade de técnico para os dados do Brasil, assim corroborando sua utilização como covariável para o cálculo do escore de propensão no processo de pareamento.

${ }^{11}$ Alguns exemplos são Caliper and Radius, Stratification e Kernel
} 
tual válido, ou seja, pouco mais de $62 \%$ do total amostrado. Dessa maneira, a amostra analisada por meio do modelo descrito no próximo estágio, foi reduzida aos casos detectados pelos critérios supramencionados de pareamento entre grupos de tratamento e de controle.

\section{Estágio II - Painel de efeito fixo com estimador diff-in-diff}

Para estabelecer os efeitos da demissão de um treinador no desempenho da equipe, começamos refletindo sobre a abordagem do modelo naive que simplesmente compara o desempenho de um clube antes e depois da dispensa do técnico, em uma mesma temporada. Essa abordagem serve como ponto de referência, porque ilustra o quão enganosa ela pode ser, ao não levar em conta a seletividade de uma demissão de técnicos e outros fatores contextuais.

Aliás, todo esse debate é importante, já que é comum presenciar na mídia esportiva em geral esse tipo de análise. Na temporada de 2018 do Campeonato Brasileiro, o modelo naive pode sugerir que a mudança de técnico do Palmeiras, Roger Machado por Luis Felipe Scolari (Felipão), no transcorrer da competição teve impacto causal sobre o resultado do clube na competição (em 2018, o Palmeiras foi o campeão). Nesse tipo de análise, se compara o antes e o depois da mudança (conforme tabela 3), no intuito de inferir acerca da eficácia da rotatividade de técnicos.

Tabela 3: Desempenho dos técnicos do Palmeiras na temporada do Campeonato Brasileiro de 2018 .

\begin{tabular}{lcc}
\hline & Roger & Felipão \\
\hline Média de gols marcados & 1,47 & 1,71 \\
Média de gols sofridos & 1 & 0,43 \\
Desempenho como mandante & $67 \%$ & $100 \%$ \\
Desempenho como visitante & $38 \%$ & $64 \%$ \\
\hline Fonte: Elaboração própria.
\end{tabular}

Fonte: Elaboração própria.

Com esse mesmo intuito, no entanto com o escopo de uma melhor identificação do efeito, foram estimados modelos lineares com dados em painel (equação (4)) em que a variável $y_{i j k}$ representa o indicador de desempenho do clube $i$, na rodada $j$, temporada $k$. A variável $t$ denota o período de tempo no qual o clube $i$ se encontra, ou seja, assumindo valor um para rodada pós-mudança e valor zero, caso contrário. Como indicadores de desempenho foram utilizados na análise o número de pontos, a diferença de gols e se a partida foi vencida ou não.

$$
y_{i j k}=\text { constante }+X_{i j k}^{\prime} \alpha+\rho t_{i j k}+\epsilon_{i j k},
$$

A vantagem de jogar em casa é altamente relevante para o desempenho (Van Ours \& Van Tuij1 2016), consequentemente, é incluído uma dummy (Mandante) que tem valor unitário para jogos disputados em casa e zero, caso contrário. Evidentemente, a qualidade do adversário também é primordial (Paola \& Scoppa 2012) e esta é aproximada pela classificação do clube na rodada (pos_adv_rodada). As duas últimas variáveis são ambas incluídas no vetor $\mathbf{X}_{i j k}^{\prime}$. 
Finalmente, $\alpha$ representa o vetor de estimativas dos parâmetros do modelo, com $\alpha_{1}$ representando a estimativa do parâmetro da variável Mandante e $\alpha_{2}$ o parâmetro estimado da variável pos_adv_rodada. $\epsilon_{i j k}$ o termo de erro e $\rho$ é o parâmetro de interesse principal, indicando se uma mudança de técnico, nesse caso, tem efeito sobre o desempenho.

Utilizou-se o mesmo modelo proposto na abordagem naive (equação (4)), porém adicionando a variável $T_{i j k}$, que indica se houve ou não uma mudança de técnico. Ou seja, passa a se trabalhar com a noção de grupos de tratamento e controle, cuja a amostra analisada está restringida aos casos de contrafactuais validados pelo modelo de pareamento do estágio inicial.

$$
y_{i j k}=\text { constante }+X_{i j k}^{\prime} \alpha+\gamma T_{i j k}+\delta t_{i j k}+\beta\left(T_{i j k} t_{i j k}\right)+\epsilon_{i j k},
$$

É importante ressaltar que na equação (5), as variáveis $T$ e $t$ aparecem tanto isoladamente quanto interagidas. Com $T$ isoladamente o parâmetro $\gamma$ capta as diferenças da média de desempenho entre os casos em que houve a mudança e o contrafactual. Enquanto o parâmetro $\delta \operatorname{com} t$ isolado interpreta a diferença de desempenho para o período anterior e posterior a mudança (real ou contrafactual). Em ambos os casos condicionados aos valores de $\mathbf{X}_{i j k}^{\prime}$ e mantendo tudo o mais constante.

Já a introdução do termo de interação procura captar o que ocorreu especificamente com o grupo de tratamento no período pós-mudança, ou seja, se a média da variável de desempenho para esse grupo em particular tornou-se diferente após a troca de treinador. Portanto, $\beta$ é o estimador de diferençasem-diferenças (Menezes et al. 2016) e nessa análise é o parâmetro de interesse principal, visto que indica se uma mudança de técnico tem efeito causal sobre o desempenho do clube. ${ }^{12}$

Um ponto relevante é que a para a execução das análises em diferentes maturidades de tempo, foi primordial impor novas restrições às observações obtidas no primeiro estágio. Para a análise de um jogo, por exemplo, foi necessário impor que não poderia haver mudanças de técnico ocorridas uma rodada imediatamente anterior à rodada da observação contrafactual.

O motivo para tal restrição é que se estamos querendo capturar o efeito de uma mudança de técnico sobre o desempenho e se uma observação contrafactual tenha sofrido uma alteração de técnico na rodada imediatamente anterior, não temos como garantir se o efeito (caso exista), é causado por essa mudança ocorrida anteriormente. Sendo assim, na análise para um jogo, três observações contrafactuais foram excluídas juntamente com as respectivas observações do grupo de tratamento.

Para facilitar o entendimento dessa restrição, segue exemplo de um caso encontrado. Na $15^{a}$ rodada da temporada de 2017, o clube Vitória-BA demitiu o até então técnico, Alexandre Gallo, após uma derrota em casa para o Grêmio por 3 a 1. Como observação contrafactual o modelo de pareamento sugeriu a $17^{\mathrm{a}}$ rodada da temporada de 2014 para o Vitória-BA. No entanto, na $16^{\mathrm{a}}$ rodada dessa temporada, o referido clube realizou uma troca de técnico após uma derrota. Logo, pela restrição imposta, excluiu-se ambas observações (real e contrafactual) do grupos de tratamento e controle.

O mesmo procedimento foi realizado nas análises para mais jogos. Na análise de dois jogos, 19 observações contrafactuais foram excluídas juntamente

\footnotetext{
${ }^{12}$ Para um maior detalhamento algébrico consulta Apêndice B.
} 
com as respectivas observações do grupo de tratamento, pelo mesmo critério relacionado anteriormente. Nesse caso, cabe um adendo, pois foi utilizada uma janela de restrição maior. Isto é, foram excluídas da análise observações contrafactuais que tinham mudanças de técnico ocorridas até duas rodadas imediatamente anterior a essa observação ou também uma rodada imediatamente posterior.

Enquanto que na análise de três jogos, 39 observações contrafactuais com as suas respectivas observações do grupo de tratamento foram excluídas. Novamente, o critério é o mesmo utilizado nas análises anteriores, porém nesse caso a janela foi ainda maior, considerando até 3 rodadas imediatamente anterior à rodada da observação contrafactual ou também até 2 rodadas imediatamente posterior a essa mesma observação.

Esse processo seguiu para as $N^{13}$ análises efetuadas, nas quais o critério é o mesmo utilizado anteriormente, tendo como única alteração a ampliação da janela de restrição. Nesse caso, considera-se até $N$ rodadas imediatamente anterior à rodada da observação contrafactual ou também $N-1$ rodadas imediatamente posterior a essa mesma observação.

\section{Resultados}

\subsection{Análise Descritiva}

A base de dados construída possui um total de 6.840 observações (o sumário com as principais estatísticas descritivas dos dados, pode ser visualizado pela Tabela 4), obtidas a partir dos 3.420 jogos, tendo 225 mudanças de técnicos distribuídas conforme Tabela 5. Inicialmente, optou-se por fazer uma distinção entre demissões e saídas de técnicos, seja em casos de consentimento mútuo ou por motivações unilaterais (como convites para treinar outros clubes ou seleções).

O intuito para tal distinção é verificar se existe ou não sobreposição entre as densidades de núcleo para a surpresa acumulada considerando mudanças de técnico. Essa informação pode ser visualizada na Figura 1(a), que mostra as densidades para todas as observações, distinguindo entre observações nas quais não ocorreram mudança de técnico em azul, as com demissão, renúncia ou resignação de técnico em vermelho e aquelas em que houve a substituição por outros motivos em verde.

Claramente na Figura 1(a) visualiza-se uma área de sobreposição entre as três distribuições. Nos casos em que houve demissão, renúncia e resignação de técnico, boa parte da densidade está sobre uma surpresa acumulada mais negativa, sendo muito semelhante nas situações em que houve mudanças por outros motivos. Os casos em que não houve demissão estão centrados mais a direita e, portanto, mais concentrados na área de surpresa acumulada positiva.

Toda essa análise faz sentido, pois é esperado que a surpresa acumulada seja em média mais baixa para os casos em que houve demissão, renúncia ou resignação, quando comparada com os outros casos, entretanto, o essencial é que exista uma área de sobreposição entre as distribuições, afim de formar os grupos de tratamento e controle.

\footnotetext{
${ }^{13} \mathrm{O} N$ total de análises foi de até 12 jogos pós-mudança de técnico.
} 
Tabela 4: Estatísticas Descritivas

\begin{tabular}{lcccccc}
\hline Variável & Mín. & $\mathbf{1}^{\mathbf{0}}$ Quartil & Mediana & Média & $\mathbf{3}^{\mathbf{0}}$ Quartil & Máx. \\
\hline id_jogo & 1 & 95,75 & 190,5 & 190,5 & 285,25 & 380 \\
rodada & 1 & 10 & 19,5 & 19,5 & 29 & 38 \\
temporada & 2009 & 2011 & 2013 & 2013 & 2015 & 2017 \\
odds_mandante & 1,11 & 1,65 & 1,97 & 2,097 & 2,39 & 9,88 \\
odds_empate & 2,93 & 3,25 & 3,37 & 3,517 & 3,66 & 7,28 \\
odds_visitante & 1,29 & 2,95 & 3,82 & 4,322 & 5,26 & 18,02 \\
site_apostas & 1 & 8 & 11 & 10,82 & 13 & 16 \\
pos_rodada & 1 & 5 & 10 & 10,4 & 15 & 20 \\
pos_adv_rodada & 1 & 5 & 10 & 10,4 & 15 & 20 \\
pts & 0 & 0 & 1 & 1,366 & 3 & 3 \\
vit & 0 & 0 & 0 & 0,365 & 1 & 1 \\
diff_gols & -6 & -1 & 0 & 0 & 1 & 6 \\
pr_vitoria & 0,05 & 0,24 & 0,353 & 0,365 & 0,479 & 0,823 \\
pr_empate & 0,12 & 0,255 & 0,277 & 0,269 & 0,287 & 0,32 \\
e_pontos & 0,277 & 1,002 & 1,353 & 1,365 & 1,718 & 2,596 \\
surpresa & $-2,471$ & $-0,969$ & $-0,347$ & 0 & 1,159 & 2,632 \\
cum_surpresa & $-18,676$ & $-2,955$ & $-0,036$ & $-0,015$ & 2,966 & 21,947 \\
cum_pts & 0 & 13 & 25 & 26,6 & 39 & 81 \\
cum_vit & 0 & 3 & 7 & 7,104 & 10 & 24 \\
cum_saldo & -58 & -5 & 0 & 0 & 5 & 42 \\
\hline
\end{tabular}

Fonte: Elaboração própria.

Figura 1: Densidades da Surpresa Acumulada considerando mudanças de técnico antes e depois do pareamento.

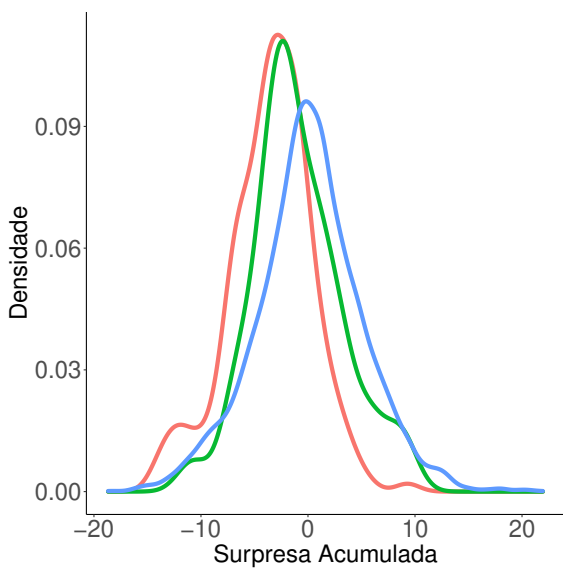

(a) Antes

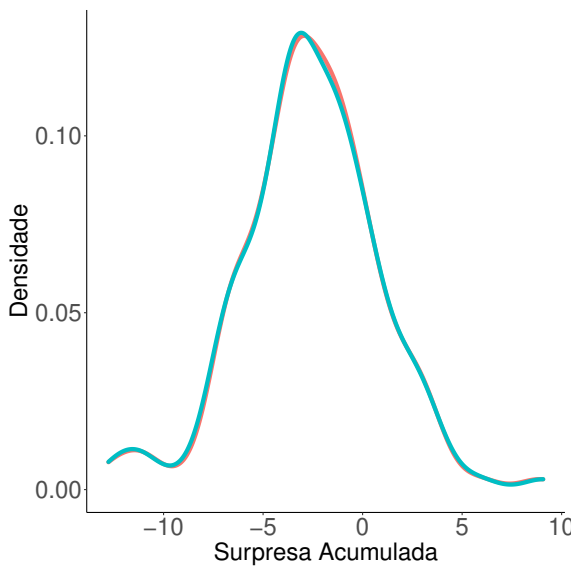

(b) Depois

Fonte: Elaboração própria. 
Pela Figura 1(b), pode-se observar uma quase total sobreposição da densidade da surpresa acumulada após a realização do pareamento, em que a densidade dos tratados está representada pelo contorno azul e dos não tratados em vermelho. Portanto, por meio da análise gráfica é possível afirmar a boa qualidade do pareamento por meio da condição de sobreposição das distribuição dos grupos de tratamento e controle.

A Tabela 5 fornece informações sobre o número de demissões e outras mudanças de técnicos por temporada. O número de mudanças de técnicos varia de 19 na temporada 2012 para 32 na temporada 2010 e 2015.

Tabela 5: Distribuição de frequências para as mudanças de técnico no Campeonato Brasileiro de Futebol entre 2009 e 2017.

\begin{tabular}{|c|c|c|c|c|}
\hline Temporada & Demissões & Saídas & Outros motivos & $\mathrm{N}^{\circ}$ de mudanças total \\
\hline 2009 & 12 & 6 & 4 & 22 \\
\hline 2010 & 15 & 4 & 13 & 32 \\
\hline 2011 & 13 & 7 & 1 & 21 \\
\hline 2012 & 13 & 5 & 1 & 19 \\
\hline 2013 & 19 & 4 & 1 & 24 \\
\hline 2014 & 18 & 4 & 1 & 23 \\
\hline 2015 & 22 & 4 & 6 & 32 \\
\hline 2016 & 14 & 6 & 9 & 29 \\
\hline 2017 & 19 & 1 & 3 & 23 \\
\hline
\end{tabular}

Fonte: Elaboração própria.

É interessante observar o quão rico em termos de amostra é o futebol brasileiro, no que tange à possibilidade de se analisar os efeitos de mudanças gerenciais. Além de estar entre as principais ligas de futebol profissional do mundo e ser reconhecidamente uma das mais disputadas ${ }^{14}$, é também a liga com a maior média de mudança de treinadores, quando comparada com as principais ligas de futebol do mundo conforme pode ser visualizado na Tabela 6 .

Tabela 6: Mudanças de treinadores nas principais ligas de futebol do mundo em 14 temporadas - 2000/2001 a 2013/2014.

\begin{tabular}{lccc}
\hline & Média & Mínimo & Máximo \\
\hline Holanda (Eredivise) & 4,2 & 2 & 7 \\
França (Ligue Um) & 4,7 & 3 & 10 \\
Inglaterra (Premier League) & 5,6 & 3 & 9 \\
Alemanha (Bundesliga) & 6,6 & 4 & 10 \\
Espanha (La Liga) & 6,7 & 4 & 9 \\
Bélgica (Jupiler League) & 6,9 & 3 & 9 \\
Itália (Serie A) & 8,4 & 5 & 12 \\
\hline
\end{tabular}

Fonte: Van Ours \& Van Tuij1 (2016).

Sendo assim, devido ao grande número de trocas de técnicos presente no futebol brasileiro, a análise sobre o efeito da rotatividade de técnico se dará por meio de uma análise em diferentes maturidades de tempo - curto, médio e longo prazo.

\footnotetext{
${ }^{14} \mathrm{Em}$ um levantamento próprio, observou-se que das 20 equipes que disputaram o Campeonato Brasileiro em 2018, 16 já foram campeãs nacional.
} 


\subsection{Efeitos da demissão do técnico no desempenho da equipe}

Análise de um jogo pós-mudança

A Tabela 7 apresenta as estimativas dos parâmetros de regressão linear do modelo naive em que o grupo de controle é ignorado. Como dito anteriormente, das 140 mudanças de técnico que inicialmente tiveram um contrafactual válido, três foram excluídas da análise de curto prazo. Portanto, foram utilizadas 137 mudanças de técnico na análise de um jogo pós-mudança. ${ }^{15}$

Tabela 7: Análise da Regressão: Modelo naive - indicadores de desempenho de um jogo pós-mudança.

\begin{tabular}{cccc}
\hline & \multicolumn{3}{c}{ Variável dependente: } \\
\cline { 2 - 4 } & Pontos & Diferença de gols & Vitória \\
& $(1)$ & $(2)$ & $0,169^{* * *}$ \\
\hline$\alpha_{1}$ & $0,587^{* * *}$ & $0,981^{* * *}$ & $(0,047)$ \\
$\alpha_{2}$ & $(0,128)$ & $(0,159)$ & $0,024^{* * *}$ \\
& $0,077^{* * *}$ & $0,091^{* * *}$ & $(0,004)$ \\
$\rho$ & $(0,011)$ & $(0,014)$ & $0,193^{* * *}$ \\
Constante & $0,498^{* * *}$ & $0,499^{* * *}$ & $(0,047)$ \\
& $(0,127)$ & $(0,159)$ & $-0,175^{* * *}$ \\
Observações & $-0,305^{* * *}$ & $-2,076^{* * *}$ & $(0,057)$ \\
$\mathrm{R}^{2}$ & $(0,154)$ & $(0,192)$ & 274 \\
Erro Padrão residual $(\mathrm{df}=270)$ & 274 & 274 & 0,198 \\
Estatística F $(\mathrm{df}=3 ; 270)$ & 0,249 & 0,264 & 0,388
\end{tabular}

Fonte: Elaboração própria. Nota: ${ }^{*} \mathrm{p}<0,1 ;{ }^{* *} \mathrm{p}<0,05 ;{ }^{* * *} \mathrm{p}<0,01$.

De acordo com a Tabela 7, todas as estimativas de parâmetro para a análise das mudanças de técnicos para um jogo são estatisticamente significativas, ou diferentes de zero. As equipes têm maior chances de vencer uma partida de uma equipe que ocupa uma posição mais baixa na tabela de classificação. Para cada posição mais baixa na tabela, o clube ganha 0,077 pontos, enquanto a probabilidade de ganhar aumenta com $2,4 \%$ e a diferença de gols aumenta para 0,091 . Se uma equipe joga em casa, espera-se receber mais 0,587 pontos do que em um jogo fora de casa contra o mesmo oponente, enquanto a equipe tem uma probabilidade $16,9 \%$ maior de vencer e tem uma diferença de gols que é 0,981 maior.

Conforme estimativa do parâmetro $\rho$ na Tabela 7 , há evidências que comprovam que o parâmetro é estatisticamente significativo e, portanto, é possível afirmar que depois de uma mudança de treinador, o desempenho da equipe é em média melhor do que antes sua troca. O número de pontos por partida é 0,498 maior, a probabilidade de ganhar é 19,3\% maior e a diferença de gols é 0,5 maior.

A Tabela 8 contém estimativas dos parâmetros para as medidas de desempenho propostas, introduzindo um grupo de controle na análise. Igualmente a análise anterior, as estimativas de parâmetro da posição do adversário na

\footnotetext{
${ }^{15}$ É importante ressaltar, que a abordagem naive poderia ser realizada utilizando todas as 225 mudanças de técnicos ocorridas entre as temporadas 2009 e 2017. Porém, por um critério de equidade, foram utilizadas apenas as mudanças de técnicos que possuíam um contrafactual válido. Nesse sentido, foram amostradas 274 observações que se referem as partidas anterior e posterior as mudanças de técnico.
} 
tabela de classificação e do efeito de uma partida em casa são estatisticamente significativas e muito semelhantes às obtidas na Tabela 7 . Devido a isso, optou-se por não focar na análise das estimativas de tais parâmetros, evitando repetições.

Tabela 8: Análise da Regressão: diff-in-diff - indicadores de desempenho de um jogo pós-mudança.

\begin{tabular}{|c|c|c|c|}
\hline & \multicolumn{3}{|c|}{ Variável dependente: } \\
\hline & $\begin{array}{l}\text { Pontos } \\
(1)\end{array}$ & $\begin{array}{c}\text { Diferença de gols } \\
\text { (2) }\end{array}$ & $\begin{array}{l}\text { Vitória } \\
\text { (3) }\end{array}$ \\
\hline$\alpha_{1}$ & $\begin{array}{l}0,706^{* * *} \\
(0,093)\end{array}$ & $\begin{array}{c}1,004^{* * *} \\
(0,115)\end{array}$ & $\begin{array}{l}0,210^{* * * *} \\
(0,035)\end{array}$ \\
\hline$\alpha_{2}$ & $\begin{array}{l}0,075^{* * *} \\
(0,008)\end{array}$ & $\begin{array}{l}0,085^{* * *} \\
(0,010)\end{array}$ & $\begin{array}{l}0,023^{* * *} \\
(0,003)\end{array}$ \\
\hline$\gamma$ & $\begin{array}{c}-0,332^{* *} \\
(0,132)\end{array}$ & $\begin{array}{c}-0,327^{* *} \\
(0,162)\end{array}$ & $\begin{array}{c}-0,129^{* * *} \\
(0,049)\end{array}$ \\
\hline$\delta$ & $\begin{array}{c}0,119 \\
(0,132)\end{array}$ & $\begin{array}{c}0,179 \\
(0,162)\end{array}$ & $\begin{array}{c}0,039 \\
(0,049)\end{array}$ \\
\hline$\beta$ & $\begin{array}{l}0,381^{* *} \\
(0,186)\end{array}$ & $\begin{array}{c}0,322 \\
(0,229)\end{array}$ & $\begin{array}{l}0,155^{* *} \\
(0,070)\end{array}$ \\
\hline Constante & $\begin{array}{l}-0,006 \\
(0,133)\end{array}$ & $\begin{array}{c}-1,701^{* * *} \\
(0,164)\end{array}$ & $\begin{array}{l}-0,056 \\
(0,050)\end{array}$ \\
\hline Observações & 548 & 548 & 548 \\
\hline $\mathrm{R}^{2}$ & 0,238 & 0,240 & 0,178 \\
\hline Erro Padrão residual ( $\mathrm{df}=542)$ & 1,090 & 1,343 & 0,407 \\
\hline Estatística $\mathrm{F}(\mathrm{df}=5 ; 542)$ & $33,807^{* * *}$ & $34,194^{* * *}$ & $23,430^{* * * *}$ \\
\hline
\end{tabular}

Fonte: Elaboração própria. Nota: ${ }^{*} \mathrm{p}<0,1 ;{ }^{* *} \mathrm{p}<0,05 ;{ }^{* * *} \mathrm{p}<0,01$.

Na análise por grupos, a amostra conteve 548 observações, em que 274 destas eram referentes ao primeiro jogo anterior e posterior à mudança efetiva de técnico (grupo de tratamento) e 274 observações referentes ao primeiro jogo anterior e posterior à ausência de tratamento (grupo de controle).

O objetivo da análise é captar o que ocorreu especificamente com o grupo de tratamento no período pós-mudança, ou seja, se a média da variável de desempenho para esse grupo em particular tornou-se diferente após a mudança de treinador. Portanto, o parâmetro $\beta$ capta o impacto da mudança.

Nesse sentido, conforme Tabela 8 , das 3 medidas de desempenho propostas na análise de um jogo pós-mudança, apenas duas delas tiveram estimativas para o parâmetro $\beta$ estatisticamente significativas, são essas: Pontos e Vitória. Portanto, há evidências que depois de uma mudança de técnico, o desempenho da equipe é em média melhor do que antes da troca. Quando comparado os grupos de tratamento e de controle, verificou-se que o primeiro teve 0,381 pontos a mais por partida e a probabilidade de vitória foi maior em 15,5\%. Os resultados encontrados não estão em consonância com os obtidos em Van Ours \& Van Tuijl (2016), em que não foram encontradas diferenças após a mudança de treinador.

Logo, diante tais evidências surge o seguinte questionamento: o fato de a mudança gerencial melhorar o desempenho em um curtíssimo prazo pode explicar a grande quantidade de demissões de técnicos no futebol brasileiro? Para respondê-lo, é necessário primeiramente entender as razões do por que técnicos são demitidos de qualquer maneira. Uma possível razão para tal questão é de que alguns clubes contratam sem critério e assim demitem sem 
compromisso. A falta de um critério na escolha de um treinador dificulta principalmente a execução ou continuidade de um padrão de trabalho. A pressão incessante por resultados imediatos faz com que alguns diretores de clubes busquem a substituição gerencial, sem qualquer compromisso, porém reconhecendo que essa pode ser eficaz de imediato, conforme os resultados obtidos na análise de um jogo.

Isso está relacionado a uma explicação teórica para o fenômeno da sucessão de lideranças denominada “Ciclo Vicioso" (Grusky 1960, 1961). Tal ideia encara a mudança de treinador como um processo desestabilizador e interruptivo das organizações. Isso devido principalmente à assimilação aos novos métodos de trabalho introduzidos pelo novo treinador. Nesse caso, os elementos das organizações terão que se adaptar a mudança, impactando nas práticas já estabelecidas e aprendidas. Isso terá efeito direto no desempenho da equipe, o que pode contribuir para uma sucessão de resultados negativos, tendo como possível consequência uma nova mudança de treinador.

\section{Análise de dois jogos pós-mudança}

É importante destacar algumas alterações quando comparada a análise anterior. Primeiramente, foram selecionadas as 2 partidas imediatamente anteriores à mudança de técnico - real e fictícia - e também as 2 partidas posteriores à mudança. A partir de então, as variáveis dependentes Pontos e Vitória estão em percentual, ou seja, Pontos representa a proporção de pontos conquistados sobre a quantidade máxima possível e Vitória representa a proporção de vitórias em 2 partidas, enquanto a variável dependente Diferença de gols representa a soma da diferença de gols em 2 partidas.

Em segundo lugar, fazendo uso da equação (5) foram realizadas mudanças nas variáveis independentes com o objetivo de juntar, nesse caso, dois jogos em uma única observação. A variável Posição do adversário, então, passa a representar a média aritmética das posições dos adversários em 2 rodadas. Já a variável Mandante é a proporção de jogos em casa dentre 2 rodadas, enquanto que as demais variáveis continuam com a mesma formatação da análise para um jogo. As mesmas alterações foram realizadas na análise para mais jogos.

Igualmente realizado na análise anterior, foram estimados os parâmetros da análise de regressão sem a inclusão do estimador diff-in-diff, no entanto, optamos por desconsiderar a apresentação da tabela afim de evitar demasias. Sendo apenas importante observar que conforme os resultados, há evidências que possibilitam afirmar que depois de uma mudança de treinador, o desempenho da equipe - nas 3 medidas - é melhor do que antes da troca.

Porém, como o objetivo é considerar a seletividade das demissões, é essencial verificar o que ocorre ao determinar um grupo de controle de técnicos que não foram demitidos. Conforme os resultados expostos na Tabela 9, das 3 medidas de desempenho propostas na análise, duas delas tiveram estimativa para o parâmetro $\beta$ estatisticamente significativa ao nível de $10 \%$. Portanto, há evidências que depois de uma mudança de técnico, aumenta-se a proporção de pontos em $8,8 \%$ e de vitórias em $12 \%$, em média.

Para a outra medida de desempenho - Diferença de gols, nada se pode afirmar acerca da relação entre a mudança de técnico e a melhora de desempenho, visto que não rejeitamos a hipótese de que o parâmetro associado a essa variável seja estatisticamente igual a zero. 
Tabela 9: Análise da Regressão: diff-in-diff - indicadores de desempenho para dois jogos pós-mudança.

\begin{tabular}{|c|c|c|c|}
\hline & \multicolumn{3}{|c|}{ Variável dependente: } \\
\hline & $\begin{array}{l}\text { Pontos } \\
\text { (1) }\end{array}$ & $\begin{array}{c}\text { Diferença de gols } \\
(2)\end{array}$ & $\begin{array}{l}\text { Vitória } \\
\text { (3) }\end{array}$ \\
\hline$\alpha_{1}$ & $\begin{array}{l}0,138^{* * *} \\
(0,030)\end{array}$ & $\begin{array}{c}0,950^{* * * *} \\
(0,219)\end{array}$ & $\begin{array}{l}0,130^{* * * *} \\
(0,034)\end{array}$ \\
\hline$\alpha_{2}$ & $\begin{array}{l}0,024^{* * *} \\
(0,003)\end{array}$ & $\begin{array}{l}0,180^{* * *} \\
(0,023)\end{array}$ & $\begin{array}{l}0,023^{* * *} \\
(0,004)\end{array}$ \\
\hline$\gamma$ & $\begin{array}{c}-0,080^{* *} \\
(0,036)\end{array}$ & $\begin{array}{l}-0,419 \\
(0,258)\end{array}$ & $\begin{array}{c}-0,096^{* *} \\
(0,040)\end{array}$ \\
\hline$\delta$ & $\begin{array}{l}0,063^{*} \\
(0,035)\end{array}$ & $\begin{array}{l}0,575^{* *} \\
(0,257)\end{array}$ & $\begin{array}{c}0,056 \\
(0,040)\end{array}$ \\
\hline$\beta$ & $\begin{array}{l}0,088^{*} \\
(0,050)\end{array}$ & $\begin{array}{c}0,393 \\
(0,364)\end{array}$ & $\begin{array}{l}0,120^{* *} \\
(0,057)\end{array}$ \\
\hline Constante & $\begin{array}{l}-0,001 \\
(0,051)\end{array}$ & $\begin{array}{c}-3,368^{* * *} \\
(0,369)\end{array}$ & $\begin{array}{l}-0,063 \\
(0,057)\end{array}$ \\
\hline Observações & 484 & 484 & 484 \\
\hline $\mathrm{R}^{2}$ & 0,190 & 0,187 & 0,152 \\
\hline Erro Padrão Residual ( $\mathrm{df}=478)$ & 0,276 & 1,999 & 0,311 \\
\hline Estatística $\mathrm{F}(\mathrm{df}=5 ; 478)$ & $22,373^{* * *}$ & $21,920^{* * *}$ & $17,118^{* * *}$ \\
\hline
\end{tabular}

Fonte: Elaboração própria. Nota: ${ }^{*} \mathrm{p}<0,1 ;{ }^{* *} \mathrm{p}<0,05 ;{ }^{* * *} \mathrm{p}<0,01$.

Análise de três jogos pós-mudança

Assim como ocorreu nas análises anteriores, as estimativas do parâmetro de mudança de técnico no modelo naive foram estatisticamente significativas e, portanto, há evidências que garantem a existência de melhora no desempenho da equipe após a mudança de técnico.

Já ao considerar a abordagem por grupos - tratamento e controle - das 3 medidas de desempenho propostas na análise de três jogos pós-mudança, nenhuma delas teve estimativa para o parâmetro $\beta$ estatisticamente significativa, conforme os resultados expostos na Tabela 10. Portanto, não se pode afirmar que uma mudança de técnico tem efeito causal sobre o desempenho da equipe, após três partidas.

É importante ressaltar que foram feitas análises para 4 jogos ou mais pósmudança, no entanto, assim como ocorreu já com a análise para três jogos, não encontrou-se evidências que demonstrem que a mudança de técnico tem efeito causal sobre o desempenho da equipe e, portanto, optou-se por ignorar a apresentação dos resultados, deixando ao leitor mais exigente a opção de visualizar os resultados a partir do endereço https : / /gi thub.com/caio-azevedo/ rotatividade_treinadores.

É importante ressaltar que o aumento da janela de análise torna mais difícil a obtenção de um contrafactual válido (pelo grande número de trocas de técnico) e como consequência o tamanho da amostra será menor. Logo, a não significância do parâmetro $\beta$ pode estar relacionada ao aumento do erro padrão ocasionado pela redução da amostra.

Aqui, depara-se com a seguinte situação: se a rotatividade gerencial não tem efeito sobre o desempenho, por que técnicos são demitidos? Os argumentos podem ser vários, porém uma explicação teórica bastante comum na literatura de rotatividade gerencial, denominada "Bode Expiatório" (Gamson \& Scotch 1964), pode explicar bem essa situação. 
Tabela 10: Análise da Regressão: diff-in-diff - indicadores de desempenho de três jogos pós-mudança.

\begin{tabular}{|c|c|c|c|}
\hline & \multicolumn{3}{|c|}{ Variável dependente: } \\
\hline & $\begin{array}{l}\text { Pontos } \\
(1)\end{array}$ & $\begin{array}{c}\text { Diferença de gols } \\
\text { (2) }\end{array}$ & $\begin{array}{l}\text { Vitória } \\
\text { (3) }\end{array}$ \\
\hline$\alpha_{1}$ & $\begin{array}{l}0,111^{* * *} \\
(0,021)\end{array}$ & $\begin{array}{c}1,308^{* * *} \\
(0,244)\end{array}$ & $\begin{array}{l}0,091^{* * *} \\
(0,024)\end{array}$ \\
\hline$\alpha_{2}$ & $\begin{array}{c}0,025^{* * *} \\
(0,004)\end{array}$ & $\begin{array}{c}0,240^{* * * *} \\
(0,042)\end{array}$ & $\begin{array}{c}0,024^{* * * *} \\
(0,004)\end{array}$ \\
\hline$\gamma$ & $\begin{array}{c}-0,066^{* *} \\
(0,030)\end{array}$ & $\begin{array}{l}-0,630^{*} \\
(0,348)\end{array}$ & $\begin{array}{r}-0,073^{* *} \\
(0,034)\end{array}$ \\
\hline$\delta$ & $\begin{array}{l}0,103^{* * *} \\
(0,030)\end{array}$ & $\begin{array}{l}1,183^{* * *} \\
(0,347)\end{array}$ & $\begin{array}{c}0,107^{* * *} \\
(0,034)\end{array}$ \\
\hline$\beta$ & $\begin{array}{c}0,053 \\
(0,043)\end{array}$ & $\begin{array}{c}0,300 \\
(0,491)\end{array}$ & $\begin{array}{c}0,072 \\
(0,049)\end{array}$ \\
\hline Constante & $\begin{array}{l}-0,037 \\
(0,054)\end{array}$ & $\begin{array}{c}-5,208^{* * *} \\
(0,613)\end{array}$ & $\begin{array}{l}-0,099 \\
(0,061)\end{array}$ \\
\hline Observações & 404 & 404 & 404 \\
\hline $\mathrm{R}^{2}$ & 0,233 & 0,203 & 0,188 \\
\hline Erro Padrão residual( $(\mathrm{df}=398)$ & 0,216 & 2,465 & 0,244 \\
\hline Estatística $\mathrm{F}(\mathrm{df}=5 ; 398)$ & $24,179^{* * *}$ & $20,311^{* * *}$ & $18,488^{* * *}$ \\
\hline
\end{tabular}

De acordo com essa explicação, diretores de clubes quando confrontados com um mau desempenho de suas equipes, tendem a expor os técnicos como o principal culpado, no intuito de amenizar a pressão ou descontentamento por parte dos torcedores. Esse fenômeno acaba por estabelecer um mecanismo de transferência de culpa das diretorias para os treinadores, quando na verdade, os maiores responsáveis pela gestão do clube por um todo, o que inclui a qualidade da equipe, são os diretores. Assim, os técnicos parecem ser demitidos por motivos alheios à sua influência. ${ }^{16}$

Outra provável razão é a concepção errada por parte de diretores. Como visto, o fenômeno denominado regressão à média causa a impressão que o desempenho após uma mudança gerencial é frequentemente melhor do que antes. Portanto, persiste um pensamento de que mudanças, em grande parte das vezes, são bem-sucedidas. E como visto, um modelo naive que simplesmente compara a performance anterior à dispensa do técnico com o desempenho após a demissão pode levar a conclusões errôneas ou diferentes, quando comparadas as análises que utilizam um grupo de controle com observações contrafactuais.

Fato é que uma comparação antes e depois sem considerar um contrafactual é enganosa do ponto de vista das pesquisas científicas, porém, independentemente de serem erradas, não são necessariamente enganosas na percepção de diretores, torcedores e meios de comunicação de massa, que desconsideram a avaliação de impacto por meio de um grupo de controle. E como observado, utilizando o modelo naive, a mudança de técnico teve impacto sobre o desempenho, logo dá total embasamento as percepções errôneas.

\footnotetext{
${ }^{16}$ Para uma discussão mais detalhada sobre o assunto utilizando como cenário o futebol brasileiro, ver Rocha et al. (2009).
} 


\section{Heterogeneidade nos efeitos: alguns exemplos}

Os resultados obtidos na seção anterior - Análise de três jogos pós-mudança - revelam que, em média, a rotatividade de técnico não tem associação com o desempenho da equipe. Porém, no caso brasileiro, tal como observado por Besters et al. (2016) para a Liga Inglesa, existe uma clara heterogeneidade nos efeitos de mudanças gerenciais quando observamos de maneira individualizada. A Figura 2 apresenta a dispersão de todas as 31 mudanças incluídas na amostra considerando a análise para oito jogos pós-mudança. O eixo vertical refere-se à surpresa acumulada no oitavo jogo após a mudança de técnico. Enquanto, o eixo horizontal indica a surpresa acumulada no oitavo jogo do cenário contrafactual.

Por uma questão de clareza, foi adicionada uma diagonal centrada na origem que indica que as coordenadas dos eixos são iguais. Portanto, observações acima da linha representam casos em que o grupo de tratamento se saiu melhor que o grupo de controle, o que sugere que as mudanças foram eficazes. Já as observações abaixo da linha representam casos em que a mudança de técnico foi ineficaz, ou seja, o grupo de tratamento se saiu pior que o grupo de controle. Além disso, a proximidade das observações com a linha diagonal indica que as mudanças (reais e fictícias) tiveram o mesmo desempenho.

Figura 2: Dispersão dos pares amostrados na Análise de LP.

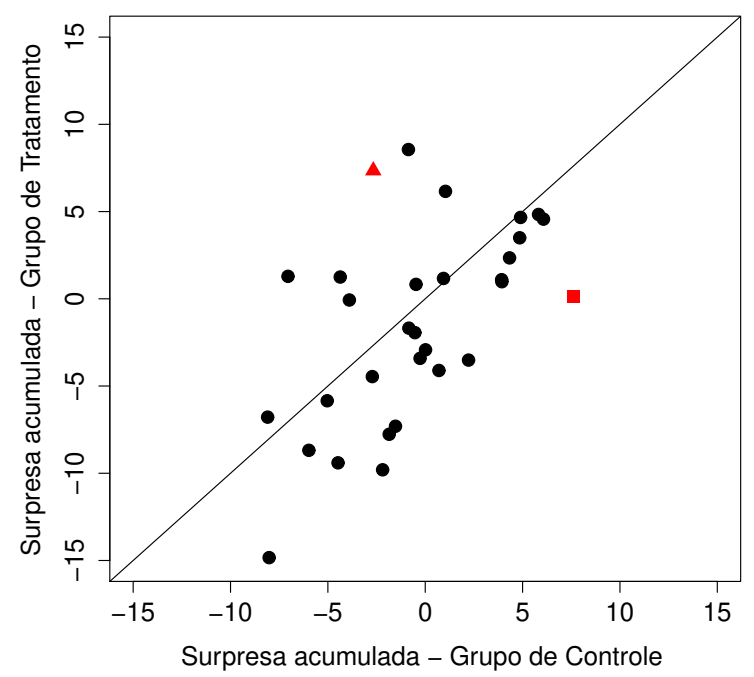

Fonte: Elaboração própria.

Por meio da Figura 2, é possível observar que boa parte das observações estão bastante próximas da linha diagonal. Tal constatação confirma o resultado encontrado na análise com uma maturidade de tempo menor ( 3 jogos pós-mudança) que, em média, uma mudança de técnico não tem efeito sobre o desempenho. No entanto, um alto número de observações está a uma distância expressiva da diagonal, o que sugere que algumas mudanças são eficazes, enquanto outras são contraproducentes. 
Nesse sentido, torna-se importante investigar se há ou não razões específicas para a eficácia da rotatividade gerencial. Para isso, selecionou-se duas substituições de técnico com resultados distintos para uma análise específica: 1) caso do Vasco da Gama (assinalado com triângulo vermelho na Figura 2) com a temporada 2017 e com o contrafactual na temporada de 2010; 2) caso do Internacional (ilustrado com quadrado vermelho na Figura 2) com a temporada 2009 e com o contrafactual na temporada 2014. A Figura 3 descreve a trajetória dos resultados desses dois casos.

Figura 3: Estudos de caso: análise da surpresa acumulada.

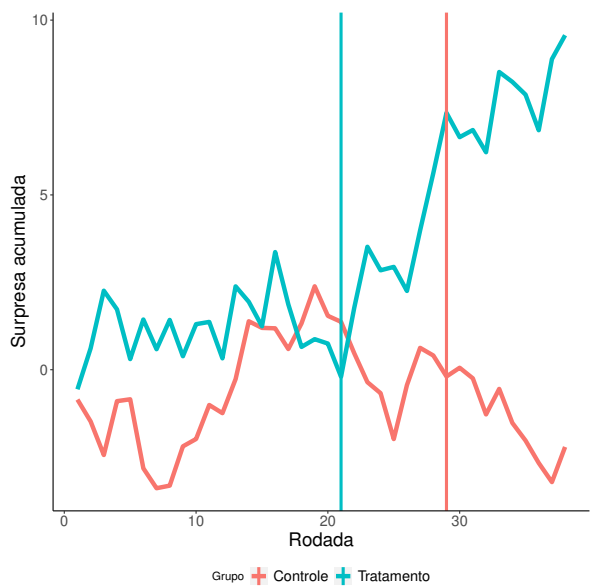

(a) Vasco

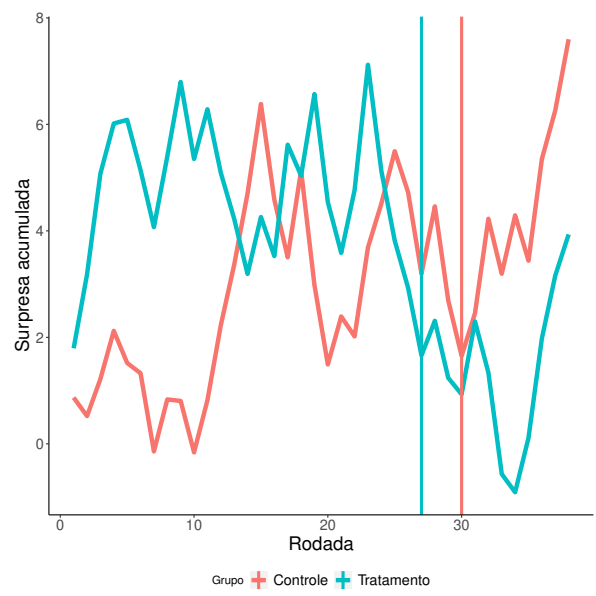

(b) Internacional

Fonte: Elaboração própria.

A Figura 3(a) mostra que a partir da mudança de técnico na temporada de 2017 (linha vertical azul), Milton Mendes por Zé Ricardo, a surpresa acumulada passa a ter um comportamento de crescimento ${ }^{17}$, enquanto ocorre o contrário com a surpresa acumulada da mudança contrafactual (linha vertical vermelha) na temporada de 2010. Um dos motivos que pode explicar a ascensão do Vasco na temporada de 2017 foi a briga para evitar mais um rebaixamento na história do clube para série $B$, enquanto que na temporada de 2010, apesar de não ter tido bons resultados, o clube não chegou a brigar contra o rebaixamento.

Por sua vez, a Figura 3(b) mostra que a partir da mudança de técnico na temporada de 2009 (linha vertical azul), Tite por Mário Sérgio, a surpresa acumulada mantém o padrão de queda até quase o fim do campeonato, tendo uma ascensão nas rodadas finais, enquanto ocorre o contrário com a surpresa acumulada da mudança contrafactual (linha vertical vermelha) na temporada de 2014, que ao manter o técnico na $30^{\text {a }}$ rodada teve acréscimos sucessivos na surpresa acumulada. Um dos motivos que pode explicar a recuperação do Internacional em 2014 foi justamente a goleada sofrida para o arquirrival Grêmio, já que a partir disso a equipe conquistou 5 vitórias consecutivas. Ou-

\footnotetext{
${ }^{17}$ Apesar da desconfiança com o novo técnico, a equipe comandada por Zé Ricardo teve uma ascensão de performance (conforme pode ser verificado pelas expectativas das casas de apostas) e em 17 partidas obteve 8 vitórias, 7 empates e apenas 2 derrotas, ou seja, um aproveitamento de $60,7 \%$ de pontos disputados, terminando o campeonato na $7^{\text {a }}$ colocação. Garantindo, inclusive, a classificação para a fase preliminar da Libertadores da América do ano seguinte.
} 
tro motivo que pode ser importante é que em 2014 o Internacional não tinha chances de título, visto que o Cruzeiro disparou na dianteira do campeonato, diferentemente de 2009. Logo, sendo um postulante ao título, cria-se uma maior expectativa de bons resultados. E foi o que ocorreu com o Internacional na temporada de 2009, quando teve derrotas em momentos onde todos esperavam por vitórias.

\section{Considerações finais}

Considerando que o caso brasileiro apresenta um comportamento atípico na taxa de rotatividade de treinadores, sobretudo quando se compara com os indicadores de equipes do campeonato Alemão, Espanhol, Inglês e Francês, temos um laboratório diferenciado para investigar o efeito das mudanças de técnicos sobre o desempenho dos clubes de futebol. Para isso, foram avaliados os efeitos da rotatividade em diferentes maturidades de tempo, a partir da comparação do desempenho na situação de tratamento com o cenário contrafactual construído, levando em conta dados da primeira divisão do futebol brasileiro entre as temporadas de 2009 e 2017.

Para a análise de um jogo após a troca, foram encontradas evidências de melhora no desempenho da equipe após a mudança de técnico. Em relação às análises para dois jogos ou mais não foram observadas diferenças no desempenho com o novo treinador. Logo, há evidências de eficácia da rotatividade gerencial sobre o desempenho no curtíssimo prazo, porém para maior maturação não se constatou evidências que garantam tal eficácia, sugerindo que resultados mais robustos da equipe estão potencialmente associados a um melhor planejamento dos jogadores e/ou outros fatores gerenciais.

Não obstante, existe um ponto relevante das evidências apresentadas neste estudo, que é justamente os diferentes resultados para curto, médio e longo prazo. Nesse sentido, é possível concluir que o fato de a mudança de técnico ser eficaz no aumento de desempenho, em curto prazo, pode traduzir a própria realidade do futebol brasileiro - de grande rotatividade de técnicos - por meio da busca de resultados imediatos. Ainda a esse respeito, foi encontrado heterogeneidade nos efeitos das mudanças gerenciais, sendo algumas eficazes e outras contraproducentes. Porém, tudo indica que os efeitos das mudanças, sejam eles positivos ou negativos, parecem estar relacionado a circunstâncias específicas e altamente imprevisíveis, conforme os casos apresentados para o Vasco da Gama e o Internacional.

\section{Referências Bibliográficas}

Alves, J. F., Cirino, J. F. \& Cassuce, F. C. C. (2019). Determinantes do aproveitamento final de pontos das equipes nos campeonatos brasileiro e argentino de futebol. Economia Aplicada, Ribeirão Preto, v. 23, n. 4, p. 113-144.

Anderson, C. \& Sally, D. (2013). Os números do jogo: por que tudo o que você sabe sobre futebol está errado. São Paulo: Paralela.

Araujo, A. F., Shikida, C. D. \& Ferreira, V. G. (2018). Determinantes das mudanças de liderança: o caso do Campeonato Brasileiro de Futebol. RBFFRevista Brasileira de Futsal e Futebol, São Paulo, v. 10, n. 37, p. 130-137. 
Audas, R., Dobson, S. \& Goddard, J. (1999). Organizational performance and managerial turnover. Managerial and Decision Economics, New Jersey, v. 20, n. 6, p. 305-318.

Balduck, A. L., Buelens, M. \& Philippaerts, R. (2010). Short-term effects of midseason coach turnover on team performance in soccer. Research Quarterly for Exercise and Sport, Abingdon, v. 81, n. 3, p. 379-383.

Besters, L. M., Van Ours, J. C. \& Van Tuijl, M. A. (2016). Effectiveness of inseason manager changes in English Premier League Football. De Economist, Cham, v. 164, n. 3, p. 335-356.

Bruinshoofd, A. \& Weel, B. T. (2003). Manager to go? Performance dips reconsidered with evidence from Dutch football. European Journal of Operational Research, Amsterdam, v. 148, n. 2, p. 233-246.

Dobson, S. \& Goddard, J. A. (2001). The Economics of Football. Cambridge: Cambridge University Press.

D'Addona, S. \& Kind, A. (2014). Forced manager turnovers in English soccer leagues: a long-term perspective. Journal of Sports Economics, Los Angeles, v. 15 , n. 2, p. $150-179$.

FIFA (2007). FIFA big count 2006. Zurich: FIFA.

Gamson, W. A. \& Scotch, N. A. (1964). Scapegoating in baseball. American Journal of Sociology, Chicago, v. 70, n. 1, p. 69-72.

Gasparetto, T. \& Barajas, A. (2018). The Determinants of Sporting Success in the Brazilian Football League. International Journal of Sport Finance, Morgantown, v. 13, n. 2.

Gertler, P., Martinez, S., Premand, P., Rawlings, L. \& Vermeersch, C. (2018). Avaliação de impacto na prática. Washington: BID.

Giovannetti, B., Rocha, B. P., Sanches, F. M. \& Silva, J. C. D. (2006). Medindo a fidelidade das torcidas brasileiras: uma análise econômica no futebol. Revista Brasileira de Economia, Rio de Janeiro, v. 60, n. 4, p. 389-406.

Google (2018). Ver o que esteve em alta em 2018 - Brasil. Disponível em: https://trends.google.com.br/trends/yis/2018/BR/. Acesso em: $31 \mathrm{de}$ janeiro de 2019.

Grusky, O. (1960). Administrative succession in formal organizations. Social Forces, Chapel Hill, v. 39, n. 2, p. 105-115.

Grusky, O. (1961). Corporate size, bureaucratization, and managerial succession. American Journal of Sociology, Chicago, v. 67, n. 3, p. 261-269.

Guzmán, I. (2006). Measuring efficiency and sustainable growth in Spanish football teams. European sport management quarterly, Abingdon, v. 6, n. 3, p. 267-287.

Itaú BBA (2018). Análise econômico-financeira dos clubes de futebol brasileiros - 2018. São Paulo. Disponível em: https://www.itau.com.br/itaubba$\mathrm{pt} /$ noticias/noticias-e-conteudo/analise-economico-financeira-dos-clubesde-futebol-brasileiros-2018. 
Kahn, L. M. (2000). The sports business as a labor market laboratory. Journal of Economic Perspectives, Nashville, v. 14, n. 3, p. 75-94.

Koning, R. H. (2003). An econometric evaluation of the effect of firing a coach on team performance. Applied Economics, Abingdon, v. 35, n. 5, p. 555-564.

Menezes, N., Foguel, M., Barros, R. P., Lima, L. \& Xavier Pinto, C. (2016). Avaliação Econômica de Projetos Sociais. São Paulo: Fundação Itaú Social.

Nascimento, J. C. H. B., Nossa, V., Bernardes, J. R. \& Sousa, W. D. (2015). A eficiência dos maiores clubes de futebol brasileiros: evidências de uma análise longitudinal no período de 2006 a 2011. Contabilidade Vista E Revista, Belo Horizonte, v. 26, n. 2, p. 137-161.

Paola, M. \& Scoppa, V. (2012). The effects of managerial turnover: evidence from coach dismissals in Italian soccer teams. Journal of Sports Economics, Los Angeles, v. 13, n. 2, p. 152-168.

Poulsen, R. (2000). Should he stay or should he go? Estimating the effect of firing the manager in soccer. Chance, Abingdon, v. 13, n. 2, p. 29-32.

Rocha, B. P., Sanches, F. A. M., Souza, I. V. \& Silva, J. C. D. (2009). Political Economy and Tenure of Coaches in Brazilian Soccer. Brazilian Review of Econometrics, Rio de Janeiro, v. 29, n. 2, p. 145-169.

Rosenbaum, P. R. \& Rubin, D. B. (1983). The central role of the propensity score in observational studies for causal effects. Biometrika, Oxford, v. 70, n. 1, p. 41-55.

Salomo, S., Teichmann, K. \& Albrechts, C. (2000). The relationship of performance and managerial succession in the German Premier Football League. European Journal for Sport Management, San Marino, v. 7, p. 99-119.

Štrumbelj, E. (2014). On determining probability forecasts from betting odds. International Journal of Forecasting, Amsterdam, v. 30, n. 4, p. 934-943.

Szymanski, S. (2003). The assessment: the economics of sport. Oxford Review of Economic Policy, Oxford, v. 19, n. 4, p. 467-477.

Szymanski, S. \& Kuper, S. (2010). Soccernomics. London: Harper Collins.

Tena, J. D. \& Forrest, D. (2007). Within-season dismissal of football coaches: statistical analysis of causes and consequences. European Journal of Operational Research, Amsterdam, v. 181, n. 1, p. 362-373.

Ter Weel, B. (2011). Does manager turnover improve firm performance? Evidence from Dutch soccer, 1986-2004. De Economist, Cham, v. 159, n. 3, p. 279-303.

Van Ours, J. C. \& Van Tuijl, M. A. (2016). In-season head-coach dismissals and the performance of professional football teams. Economic Inquiry, New Jersey, v. 54, n. 1, p. 591-604. 


\section{Apêndice A Determinantes da demissão de técnico}

Fora utilizada no estudo dos determinantes da demissão de técnico análise de Regressão por meio dos Modelos Probit e Logit. O intuito desta utilização é apenas verificar se as variáveis já evidenciadas por outros autores são significativas ao estimar a probabilidade de um técnico ser demitido, em especial a surpresa acumulada, que fora utilizada como covariável para estimar o escore de propensão.

Tabela A.1: Análise da Regressão: Modelos Probit e Logit.

\begin{tabular}{lcc}
\hline & \multicolumn{2}{c}{ Variável dependente: } \\
\cline { 2 - 3 } & \multicolumn{2}{c}{ Mudança de técnico } \\
& Logit & Probit \\
& $(1)$ & $(2)$ \\
\hline Surpresa acumulada & $-0,044^{* *}$ & $-0,021^{* *}$ \\
Pontos nos últimos 4 jogos & $(0,019)$ & $(0,009)$ \\
& $-0,302^{* * *}$ & $-0,135^{* * *}$ \\
Derrota como mandante & $(0,041)$ & $(0,019)$ \\
& $0,657^{* * *}$ & $0,297^{* * *}$ \\
Saldo de gols & $(0,159)$ & $(0,075)$ \\
& $-0,464^{* * *}$ & $-0,215^{* * *}$ \\
Posição do adversário & $(0,061)$ & $(0,029)$ \\
& $0,053^{* * *}$ & $0,023^{* * *}$ \\
Constante & $(0,014)$ & $(0,007)$ \\
& $-3,309^{* * *}$ & $-1,777^{* * *}$ \\
\hline Observações & $(0,277)$ & $(0,127)$ \\
Log verossimilhança & 5.400 & 5.400 \\
\hline Fonte: Elaboração própria. Nota: ${ }^{*} \mathrm{p}<0,1{ }^{* * *} \mathrm{p}<0,05 ; * * 0$ & $-661,869$ \\
\hline
\end{tabular}

\section{Apêndice B Magnitude do impacto em um modelo DD}

Considere o modelo DD por meio de regressão linear, conforme abaixo:

$$
Y_{i t}=X_{i t}^{\prime} \alpha+\gamma T_{i}+\rho t_{t}+\beta\left(T_{i} t_{t}\right)+\epsilon_{i t},
$$

em que $t$ denota o período de tempo no qual o indivíduo (ou unidade de observação) $i$ se encontra, assim a variável $t$ é binária, assumindo valor um no período pós-programa e valor zero, caso contrário. Já $T$ também é uma variável binária que assume valor unitário, se o indivíduo é tratado, e zero, caso contrário.

Logo considerando tais informações, temos o valores esperados condicionais, como:

Tratamento, pré-programa:

$$
E[Y \mid X, T=1, t=0]=X^{\prime} \alpha+\gamma+E[\epsilon \mid X, T=1, t=0]=X^{\prime} \alpha+\gamma
$$

Tratamento, pós-programa: 


$$
\begin{aligned}
E[Y \mid X, T=1, t=1] & =X^{\prime} \alpha+\gamma+\rho+\beta+E[\epsilon \mid X, T=1, t=1] \\
& =X^{\prime} \alpha+\gamma+\rho+\beta
\end{aligned}
$$

Controle, pré-programa:

$$
E[Y \mid X, T=0, t=0]=X^{\prime} \alpha+E[\epsilon \mid X, T=0, t=0]=X^{\prime} \alpha
$$

Controle, pós-programa:

$$
E[Y \mid X, T=0, t=1]=X^{\prime} \alpha+\rho+E[\epsilon \mid X, T=0, t=1]=X^{\prime} \alpha+\rho
$$

em que considerou a hipótese de média condicional nula, ou seja, $E[\epsilon \mid X, T, t]=$ 0 . Assim, calculando a dupla diferença:

$$
\begin{aligned}
{\left[\left(X^{\prime} \alpha+\gamma+\rho+\beta\right)\right.} & \left.-\left(X^{\prime} \alpha+\gamma\right)\right]-\left[\left(X^{\prime} \alpha+\rho\right)-\left(X^{\prime} \alpha\right)\right] \\
& =\rho+\beta-\rho=\beta
\end{aligned}
$$


